\section{Virilizing ovarian fibrothecoma with minor sex cord elements in a 13 year old girl: a rare case}

\author{
Neelam Sood, ${ }^{1}$ Jitendra Singh Nigam, ${ }^{2}$ \\ Geetika Goyal, 1 Reeta Ranjan ${ }^{3}$ \\ 1Department of Pathology, Deen Dayal \\ Upadhyay Hospital, Hari Nagar, New \\ Delhi; 2Department of Pathology, \\ Saraswathi Institute of Medical Sciences, \\ Anwarpur, Hapur, UP; ${ }^{3}$ Department of \\ Obstetric And Gynecology, Deen Dayal \\ Upadhyay Hospital, Hari Nagar, New \\ Delhi, India
}

\begin{abstract}
Fibrothecoma accounts for $3-4 \%$ of all ovarian neoplasms; it is usually hormonally inactive, but can be estrogenic or sometimes androgenic (11\%); it is rare under 30 years. In a very few cases, minor sex cord elements (less than $10 \%$ of the tumor area) are present; therefore, it is considered as a separate subgroup of stromal tumors. The importance of immunohistochemistry in recognizing this kind of tumor has been fully documented, with variable results on inhibin staining, but specific positivity for calretenin in such cases. We report here the rare case of a 13 -year-old child with ovarian fibrothecoma and minor sex cord stromal elements, who showed negativity for inhibin and positivity for calretenin.
\end{abstract}

\section{Introduction}

Sex cord stromal tumors represent approximately only $8 \%$ of all ovarian neoplasms, and are composed of granulosa, theca, Sertoli and leydig cells, together with fibroblasts, singly or in combination. ${ }^{1}$ Fibromas and thecomas may show a significant morphologic overlap, which has led to the use of the term fibrothecoma. This kind of tumor accounts for 3-4\% of all ovarian neoplasms. ${ }^{2}$ Another subgroup, which was first described by Young and Scully, comprises fibroma/fibrothecomatous with minor $(<10 \%)$ sex cord elements; it is designated as stromal tumor with minor sex cord elements. ${ }^{1}$ On examination, it contains discrete tubules or small nests of cells resembling granulosa cells, Sertoli cells, or indifferent cells of sex cord type with or without steroid hormone-cell type in the spindled stroma. ${ }^{3}$ This group is usually hormonally inactive, but functional differentiation in producing hormones by luteinized theca cells or leydig cells determines its course.1,2,4
To the best of our knowledge, only 14 cases of ovarian stromal tumor with minor sex cord elements have been documented till date, with only 3 cases of fibrothecoma with minor sex cord elements. ${ }^{3,5,6}$ Even though $11 \%$ of fibrothecoma can be androgenic, no case of virilizing fibrothecoma with minor sex cord elements has been found in the previous literature. ${ }^{4-10}$

The immunohistochemistry using calretenin, inhibin, vimentin, smooth muscle actin, CD10, EMA and CK has been found to be useful in ruling out differential diagnosis of adenofibromas, Brenner's tumor and other sex cord neoplasms. ${ }^{7}$ This report enlarge the existing list of similar uncommon tumors, and demonstrates superiority of calretenin over inhibin in such cases.

\section{Case Report}

A 13-year-old, unmarried, female patient presented with complaints of oligomenorrhoea, masculinizing features of enlarged clitoris, facial hair, deep voice and rapidly growing abdominal lump in left side since one month. Magnetic resonance imaging revealed normal right ovary and a $10-\mathrm{cm}$ neoplastic isointense to hypointense capsulated mass in the left ovary. Uterus and cervix were unremarkable. Hormonal study showed CA 125-37.5 IU/mL, AFP 8.6 ng/mL, HCG-4 IU/L and testosterone $1196 \mathrm{ng} / \mathrm{mL}$. Unilateral salpingooophorectomy was done and specimen was sent for histological examination. Histologically, these cases usually show predominant luteinized/steroid cells with less than $5 \%$ area of sertoliform cells

\section{Gross}

Received ovarian mass measuring $10 \mathrm{~cm}$ in diameter with attached tube. Outer surface was nodular. Cut surface was solid with focal cystic and hemorrhagic areas (Figure 1a).

\section{Histology}

Sections examined from ovary showed a well-encapsulated mass with proliferation of plumped, ovoid to spindle cells arranged in bundles and fascicles forming nodules, with mild degree of anisonucleosis and hyperchromasia and infrequent mitosis and lacking nuclear grooving. A few interspersed large, polygonal cells with pale cytoplasm (luteinized/steroid cells), lacking reinke's crystalloids were also seen. Tiny foci of cuboidal cells (less than 5\%) arranged in cords, micro and macrotubules (sertoliform cells of intermediate differentiation) were seen at the periphery (Figure 1b-d). Reticulin fibers showed pericellular pattern in spindle cell area with grouping around sertoliform cells. Spindle cells were positive for vimentin,
Correspondence: Jitendra Singh Nigam, Department of Pathology, Saraswathi Institute of Medical Sciences, Anwarpur, Hapur, UP, India.

Tel.: +91.996.852.6588.

E-mail: nigamjs@gmail.com

Key words: estrogenic, immunohistochemistry, inhibin, calretenin.

Contributions: the authors contributed equally.

Conflict of interests: the authors declare no potential conflict of interests.

Received for publication: 17 April 2014.

Revision received: 3 July 2014.

Accepted for publication: 23 July 2014.

This work is licensed under a Creative Commons Attribution NonCommercial 3.0 License (CC BYNC 3.0).

@CCopyright N. Sood et al., 2014

Licensee PAGEPress, Italy

Pediatric Reports 2014; 6:5447

doi:10.4081/pr.2014.5447

weakly for inhibin, but negative for calretenin, CD34 and cytokeratin. Strong positivity for calretenin was seen in sertoliform cells and in pale, luteinized, steroid cells. However, these sertoliform cells were inhibin, cytokeratin, vimentin and S-100 negative, though steroid cells were strongly inhibin positive (Figure 2). On the basis of histology and immunohistochemistry, final diagnosis of ovarian fibrothecoma with minor sex cord stromal elements was made.

All masculinizing features were significantly reduced in post operative follow-up of four months. Ostradiol was $100.96 \mathrm{pg} / \mathrm{mL}$ and testosterone dropped to $5 \mathrm{ng} / \mathrm{dL}$. She hasn't reported back to our center again.

\section{Discussion}

Young and Scully were the first to describe ovarian stromal neoplasms, predominantly fibromatus or thecomatous tumors, containing scattered minor sex cord elements (as above) in less than $10 \%$ of the tumor area, with the age of presentation ranging from 16 to 65 years, with a mean age of 59 years. ${ }^{3}$ These patients generally present with abdominal pain, bleeding per vaginum and adnexal mass es, rarely with androgenic features. 3,8

However, in the present case, the patient was only 13 years old, much younger than usual, and she presented with oligohypomenorrhoea, masculinizing features and abdominal lump. These tumors are usually hormonal- 


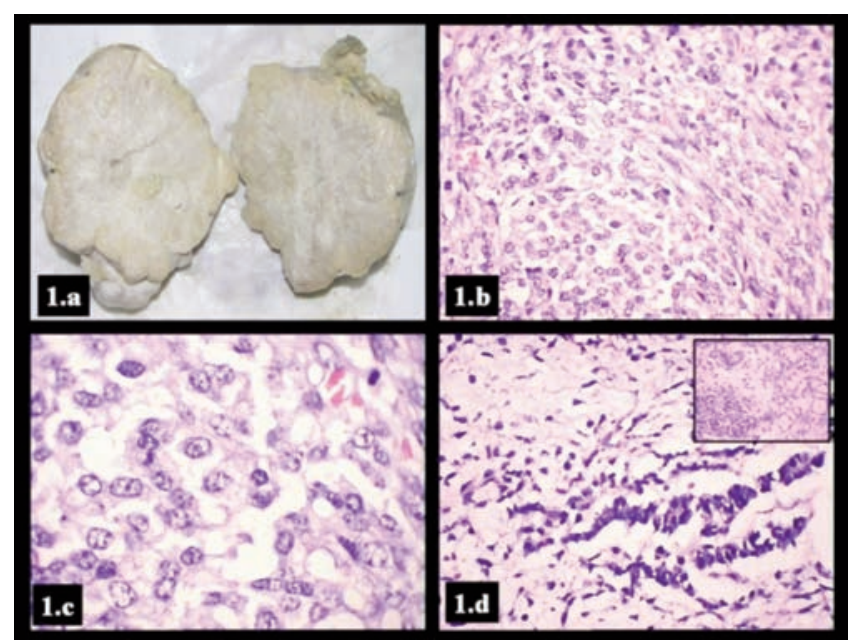

Figure 1. a) Gross: solid ovarian mass with nodular surface and cut surface show grayish white and yellowish areas; b) spindle cells admixed with plump cells with pale cytoplasm lacking reinke crystalloids and (Hematoxylin \& Eosin, 400x); c) large, pulmp polygonal cells with pale cytoplasm lacking reinke crystalloids (Hematoxylin \& Eosin, 1000x); d) sertoliform cells of intermediate differentiation with cords, micro and macrotubules of sertoliform cells (inset) (Hematoxylin \& Eosin, 400x).

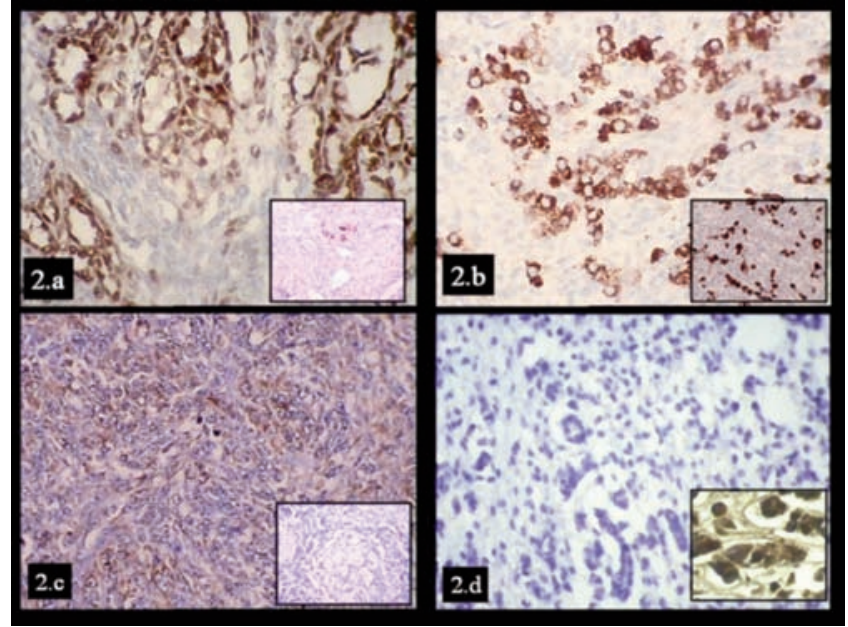

Figure 2. a) Calretenin [BioGenex Polyclonal rabbit] positivity in macrotubules cells which are inhibin [BioGenex R1 mouse IgG2a] negative (inset) $(400 \times)$; b) steroid cells strongly positive for inhibin as well as for calretenin (inset) $(400 \times)$; c) vimentin [BioGenex V9 mouse IgG1] positivity in spindle cells and negative in macrotubules (inset) $(400 \times)$; d) sertoliform cells of intermediate differentiation and microtubules showing negative inhibin staining $(400 \times)$ and strong calretenin positivity (inset) $(1000 \times)$. ly inactive, but have been occasionally associated with estrogenic features, e.g. endometrial hyperplasia or diffuse complex atypical hyperplasia or even adenocarcinoma. ${ }^{1,5,9}$ In the present case, tumor was hormonally active, but with masculinizing features and with postoperative correction.

Out of seven reported cases of fibromatous tumors of the ovary by Young et al, 3 five cases were ovarian fibroma with minor sex cord elements. Two of them were luteinized thecomas with steroid-hormone cell types without reinke's crystalloids, as in this case, and stromal-leydig cell tumor with steroid-hormonecell type with reinke's crystalloids, but sertoliform areas were not described in these two cases unlike this case. ${ }^{3}$

Zhang et al. ${ }^{8}$ reported fifty cases of ovarian stromal tumors and found steroid hormone secreting cells in a background of predominant of pattern of fibroma/thecoma. He also reported the cases of steroid cells without reinke's crystalloids, as found in the present case. ${ }^{8}$ However, combination of sertoliform cells and steroid cells/theca cells, as in our case, have not been described by them, but only recently by Sherwani et al. (without virilization). 6

This tumor was highly cellular composed of uniform spindle cells, arranged in sheets and intersecting fascicles, with scant to moderate amount of eosinophilic cytoplasm, elongated nuclei without nuclear atypia or significant mitosis and focal thin collagen with a minor component of sertoliform cells as observed by
Sherwani et al.5,6 Sex cord elements can vary from fully differentiated granulosa cells to indifferent tubular structure resembling immature Sertoli cells, and form less than $10 \%$ of the tumor area as per diagnostic criteria.1,3 On immunohistochemistry, the spindled cells in these tumors show diffusely positivity for smooth muscle actin (SMA), weak expression of vimentin and are negative for epithelial membrane antigen (EMA) and cytokeratin (CK) as also noted by us. Minor sex cord element cells have also been reported to be positive for calretenin, CD 56, CD 99, antikeratin antibody $\mathrm{KL}_{1}$ and $\mathrm{MIC}$ and negative for Vimentin, SMA and EMA, as in this case. ${ }^{9}$ However, inhibin positivity was seen in luteinized cells and not in sertoliform areas and spindle cells, unlike positivity reported by majority. Calretenin has been found to be more specific in sex cord elements and detected even in inhibin negative cells as in this case. ${ }^{10}$ The differential diagnosis includes ovarian fibromatosis, adenofibromas, Brenner's tumor. 6,7

Ovarian fibromatosis may closely resemble as they envelops follicles and their derivatives unlike fibrothecomas where the normal follicles cannot be identified. ${ }^{6}$ Ovarian adenofibroma has variable sized, larger and well described glandular elements within the proliferation of fibroblastic cells. ${ }^{3}$ Both these entities are inhibin and calretenin negative. Brenner tumor may show an abundant fibrothecomatous or luteinized thecomatous stroma with rounded to elongated, sharply demarcated, and small nests of epithelial cells of transitional cells, mucinous cells or both with a solid pattern or a central lumen, EMA and CK positive. ${ }^{6}$ These tumors, like fibromas, are thought to behave in a benign fashion and have a good prognosis. ${ }^{1}$

Alpha inhibin cannot be used alone to identify sex cord stromal cells as found in this case, as calretenin was found to be more superior and specific for these elements. ${ }^{10}$ Andra et al. ${ }^{1}$ described that bilaterality of ovarian fibrothecoma with bilateral pleurisy is also associated with a particular high elevated serum CA-125, but in the present case there was no contralateral ovary involvement in our case

The awareness about this entity along with judicious use of immunohistochemistry helps in avoiding misdiagnosis. Incidental presence of sex cord elements in the ovarian stromal tumor needs to be confirmation both by inhibin and calretenin to categories this distinct entity. Rare occurrence of this lesion in younger age group needs to work up properly.

\section{References}

1. Tavassoli FA, Mooney E, Gersell DJ, et al. Stromal sex cord tumours. In: Tavassoli FA, Devilee P, eds. WHO pathology and genetics of tumours of the breast and female genital. 1st ed. Lyon: IARC Press; 2003. 
pp.152-153.

2. Young RH. Sex cord-stromal, steroid cell, and other ovarian tumors with endocrine, paraendocrine, and paraneoplastic manifestations. In: Kurman RJ, Ellenson LH, Ronnett BM, eds. Blaustein's pathology of the female genital tract. 6th ed. London: Springer; 2011. pp 786-841.

3. Young RH, Scully RE. Ovarian stromal tumors with minor sex cord elements: a report of seven cases. Int J Gynecol Pathol 1983;2:227-34.

4. Salim S, Shantha GPS, Patel AD, et al. Virilizing ovarian steroid cell tumor in a 40 year old South Indian female: a case report. Cases J 2009;2:7521.

5. Lee HY, Ahmed Q. Fibrosarcoma of the ovary arising in a fibrothecomatous tumour with minor sex cord elements: a case report and review of the literature. Arch Pathol Lab Med 2003;127:81-4.

6. Sherwani RK, Kumar A, Afroz N, et al. Luteinized fibroma of the ovary with minor sex cord elements: an incidental finding. Clin Ovar Cancer 2011;4:41-3.

7. Gupta N. Bilateral ovarian fibroma with minor sex cord elements: an unusual neoplasm. JCDR 2012;6:1064-5.

8. Zhang J, Young RH, Arseneau J, Scully RE. Ovarian stromal tumors containing lutein or Leydig cells (leuteinized thecomas and stromal Leydig cell tumors): a clinicopathological analysis of fifty cases. Int $\mathrm{J}$ Gynecol Pathol 1982;1:270-85.
9. Kawatra V, Gupta P, Khurana N. Fibroma with minor sex cord elements: a case report and review of the literature. Cases $\mathrm{J}$ 2008;1:264.

10. Movahedi-Lankarani S, Kumaran RJ. Calretenin, a more sensitive but less specific marker than alpha-inhibin for ovarian sex cord-stromal neoplasms: an immunohistochemical study of 215 cases. Am J Surg Pathol 2002;26:1477-83.

11. Andra V, Loue S, Gbary E, et al. Bilateral ovarian fibrothecoma associated with ascites, bilateral pleural effusion and marked elevated serum CA-125. Case Rep Obstet Gynecol 2013;2013:189072. 